\title{
Positron emission tomography/computed tomography (PET/CT) in the head and neck
}

Nuray BAYAR MULUK

Department of Otolaryngology, Kırıkkale University, School of Medicine, Kırıkkale,

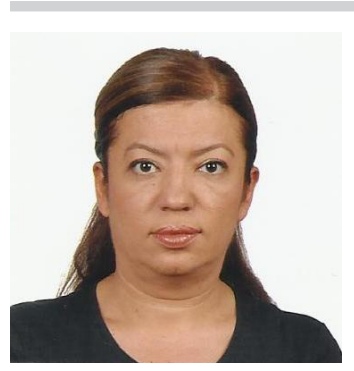

Positron emission tomography/computed tomography (PET/CT) is carried as injection of positron-emitting radionuclides, such as (18) F-fluorodeoxyglucose (FDG). Positron-emitting radionuclides are taken by metabolically or functionally active tissues. These emissions are detected and three dimensional images are obtained by reconstruction techniques. In head and neck malignancies, it has a sensitivity of $77 \%-96 \%$ and a specificity of $82 \%-100 \%$ for detection of cervical lymph node metastasis [1,2]. PET/CT is as sensitive and specific as Computed Tomography (CT) and Magnetic Resonance Imaging (MRI) for detection of primary head and neck tumors [3,4]. False negativities are also seen in necrotic or cystic lymph nodes, lymph nodes less than $5 \mathrm{~mm}$, and tumors of low metabolic activity [5]. Yongkui et al [6] performed a metaanalysis including 14 articles and 742 patients with head and neck cancer. They concluded that (18) FDG-PET/ CT had good diagnostic performance for the detection of regional nodal metastasis in patients with primary head and neck cancer before treatment. Fletcher et al [7] reported that PET/CT should be used to detect distant metastasis; and it should be performed additionally to the CT and MRI.

To evaluate PET/CT images, SUVmax value is important. Joo et al [8] reported that SUVmax value of 2.25 predicts extracapsular spread of cancer from the lymph nodes. Whereas, Dequanter et al [9] reported that (18) F-FDG PET/CT SUVmax cutoff value was 4.15 for cervical lymph node metastasis and extracapsular spread in head and neck cancer patients. Clark et al [10] reported that elevated nodal SUVmax is a significant predictor of human papillomavirus (HPV) / p16 positive disease in oropharyngeal squamous cell carcinoma.

In this issue of the Turkish Journal of Clinics and Laboratory, Açıkalın et al wrote a review entitled the usage of PET/CT imaging in head and neck cancer. They mentioned that PET/CT is progressively becoming on routine usage in head and neck cancer staging. By the help of PET/CT, cancer staging can be made easier by whole body scanning, by characterization of the lymph nodes accurately by showing the presence of head neck tumors. They also presented their case of primary unknown neck mass. In their case, PET/CT showed excessive involvement of the tongue base and diagnosed as moderately differentiated squamous cell carcinoma according to Açıkalın, et al's paper. I recommend readers of our Journal to read Açıkalın, et al's paper carefully to update their knowledge for usage of PET/CT in head and neck cancer patients.

By recent advances in medicine, PET/CT is used in routine diagnosis modality for the head and neck cancer in terms of primary and recurrent tumors, nodal and distant metastasis. As it is an expensive diagnosis tool, the usage algorithms should be followed carefully.

\section{References}

1. Ng SH, Yen TC, Liao CT, Chang JT, Chan SC, Ko SF. 18F-FDG PET and CT/MRI in oral cavity squamous cell carcinoma: a prospective study of 124 patients with histologic correlation. J Nucl Med 2005; 46: 1131-43.

2. $\mathrm{Ng} \mathrm{SH}$, Yen TC, Chang JT, Chan SC, KO SF, Wang HM. Prospective study of (18) fluorodeoxyglucose positron emission tomography and computed tomography and magnetic resonance imaging in oral cavity squamous cell carcinoma with palpably negative neck. J Clin Oncol 2006; 24: 4371-6.

3. Rudmik L, Lau HY, Matthews TW, et al. Clinical utility of PET/CT in the evaluation of head and neck squamous cell carcinoma with an unknown primary: a prospective clinical trial. Head Neck 2011; 33: 935.

4. Yabuki K, Tsukuda M, Horiuchi C, et al. Role of 18F-FDG PET in detecting primary site in the patient with primary unknown carcinoma. Eur Arch Otorhinolaryngol 2010; 267: 1785.

5. Poon CS, Stenson KM. Overview of the diagnosis and staging of head and neck cancer. In: Brockstein BE, Fried MP (Eds.). UpToDate. (Accessed online at October 10, 2015).

6. Yongkui L, Jian L, Wanghan, Jingui L. 18FDG-PET/CT for the detection of regional nodal metastasis in patients with primaryhead and neck cancer before treatment: a meta-analysis. Surg Oncol 2013; 22: e11-6.

7. Fletcher JW, Djulbegovic B, Soares HP, et al. Recommendations on the use of 18F-FDG PET in oncology. J Nucl Med 2008; 49:480-508.

8. Joo YH, Yoo IR, Cho KJ, Park JO, Nam IC, Kim MS. Extracapsular spread and FDG PET/CT correlations in oral squamous cell carcinoma. Int J Oral Maxillofac Surg 2013; 42: 158-163.

9. Dequanter $D$, Shahla $M$, Aubert $C$, Deniz $Y$, Lothaire P.Prognostic value of FDG PET/CT in head and neck squamous cell carcinomas. Onco Targets Ther 2015; 8: 2279-83.

10. Clark J, Jeffery CC, Zhang H, et al. Correlation of PET-CT nodal SUVmax with p16 positivity in oropharyngeal squamous cell carcinoma. J Otolaryngol Head Neck Surg 2015; 44: 37. 